\title{
Application of AHP in the Design of a Strategy Map
}

\author{
Luis E. Quezada ${ }^{1}$, Pedro I. Palominos ${ }^{1}$, Miguel A. Gonzalez ${ }^{2}$ \\ ${ }^{1}$ Department of Industrial Engineering, University of Santiago of Chile, Santiago, Chile; ${ }^{2}$ School of Industry, Andres Bello Univer- \\ sity, Santiago, Chile. \\ Email: luis.quezada@usach.cl
}

Received July, 2013

\begin{abstract}
This paper presents an application of the Analytic Hierarchy Process (AHP) to support the creation of a strategy map. A strategy map is a representation of the cause-effect relationships between strategic objectives of a Balanced Scorecard (BSC). The method proposed establishes the relationships that are important within the strategy map. The case of seven companies is presented, where the method is applied and the results are compared with the actual maps defined by the companies. The comparison is made to determine in which extend the proposed method is useful for establishing the causal relationships in a strategy map.
\end{abstract}

Keywords: Analytic Hierarchy Process; Strategy Map; Balanced Scorecard

\section{Introduction}

Neely [1] in his review of the ISI Web of Science database found 1352 papers published in 546 different journals containing the phrase "performance measurement" in their title, abstract or keywords. This is a measure of the importance of the subject in the literature. He also found that more than $80 \%$ of these papers were published after January 1995, which means that the subject has been received attention only recently. The Balanced Scorecard (BSC) is the performance measurement system most cited in the literature and that has become very popular among practitioners. [1,2]. The BSC [3,4] was developed by Kaplan and Norton originally as management control system, but it has developed to become a complete strategic management system [5-7].

The strategy map is part of the BSC. It is composed of a set of strategic objectives linked by cause-effect relationships [8]. The relationships are defined by managers of firms in a subjective matter [9]. In the same way, Quezada et al. [10] propose a methodology to build a strategy map, based on the way companies actually do it.

In the literature, it was found that a small number of authors use quantitative methods to model performance measurements. Some of them use the Analytic Hierarchy Process (AHP) [11,12], such as those proposed by Cheng et al. [13], Bittici et al. [14] Lee et al. [15], Sarkis [16] and Temur et al. [17]. Others such as Yurdakul [18] and Yurdakul and Ic [19] use the Analytic Network Process (ANP) [20]. Other authors, such as Huang et al., [21], Tseng [22] and Yüksel and Dagdeviren [23] utilize AHP/ ANP to support the modeling of a Balanced Scorecard.
In all the cases where AHP and/or ANP are used, the relationships are pre-defined so what they do is to assign priorities to the strategy objectives. In this work, a mechanism to get those relevant relationships is proposed.

As stated above, a strategy map is a graphical representation of the strategy of a firm. It contains strategic objectives, which are classified into four perspectives: (a) Finances, (b) Clients, (c) Internal Processes and (d) Growth \& Development. The objectives are linked according to a causal relationship.

Figure 1 shows a representation of a strategy map, where the nodes correspond to strategic objectives and the arcs correspond to cause-effect relationships.

The strategy map is modeled as hierarchy, where all the nodes of one level are initially connected to all the levels of the immediate lower level. An initial node is added (level 0).

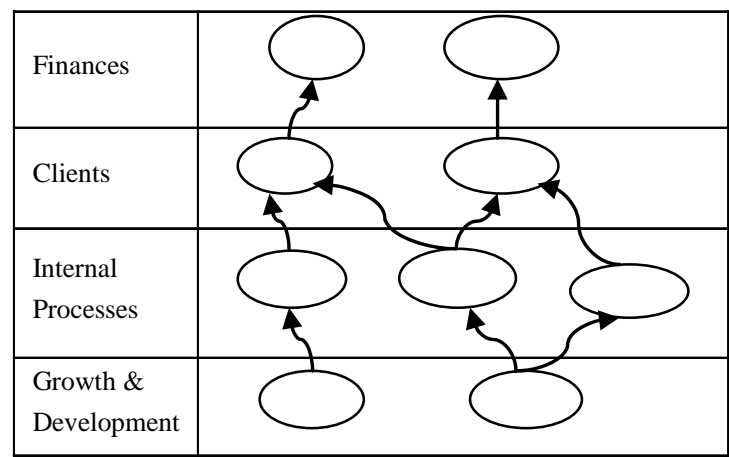

Figure 1. Strategy map. 
Figure 2 shows an example of a hierarchical model. What the method does is to estimate the "priority" of every arc and select those that are "more important".

\section{The Method}

The method works at follows:

For the top node (level 0) and level 1:

$w_{j}^{1}=$ priority of node $\mathrm{j}$ of level 1

For any level $\mathrm{K}$ and level $\mathrm{K}+1$, let's consider a node $\mathrm{j}$ and a node i ( Figure 3).

Using AHP techniques, the importance of any node $\mathrm{i}$ in relation to a node i can be estimated.

Let

$a_{i j}=$ importance of node $i$ in relation to a parent node $j$

$w_{j}^{K}=$ importance of node $\mathrm{j}$ in level $\mathrm{K}$

The importance of the relationship between a node $j$ and a node $\mathrm{i}$ is calculated as:

$$
b_{i j}=\mathrm{a}_{i j} w_{j}^{K} \forall \mathrm{i}, \mathrm{j}
$$

Clearly

$$
\sum_{i} b_{i j}=1 \forall \mathrm{j}
$$

The next step is the selection of those relationships (arcs) that are "important". The arcs i-j with the highest importance that account for the $80 \%$ of the importance are selected. This calculation is repeated for all the levels.

However, in a strategy map, there must be always a path from any node to the top node, but this method may fail in doing this. So, when a node is not connected, the arc with the highest importance connected to it is added.

This is a variation of the method proposed by Quezada and Quintero [24], who uses a different method for selecting the "important" arcs they do not make any validation of their proposal, which is the main purpose of this work.

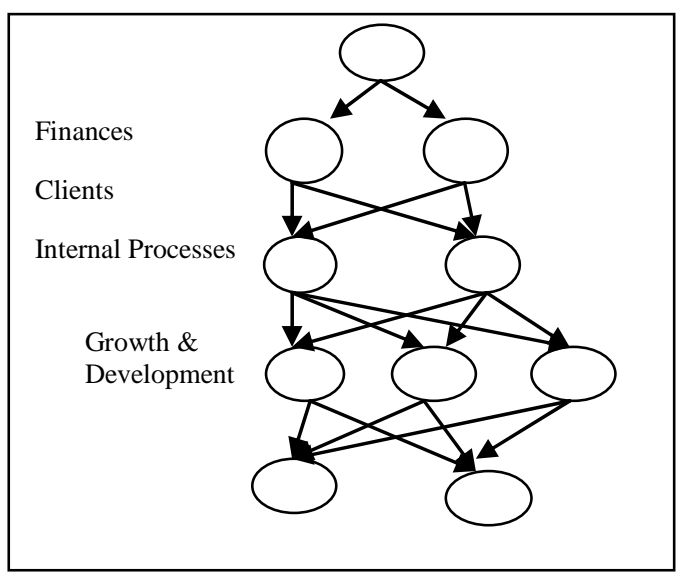

Figure 2. Hierarchical model of a strategy map.

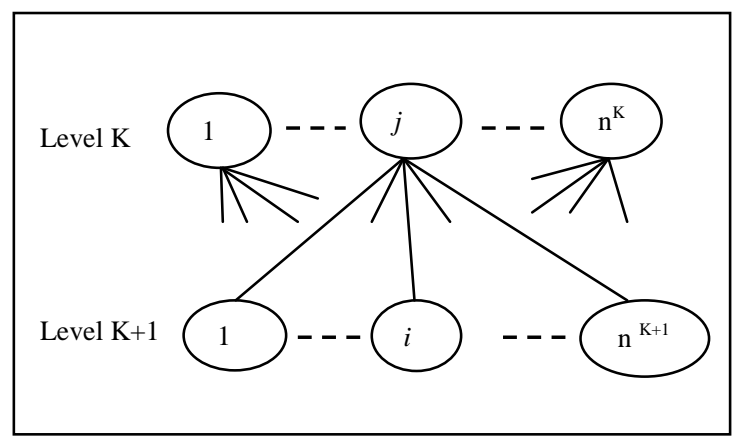

Figure 3. Relationships between levels.

\section{Evaluation of the Method}

The method was applied in 7 companies. They will be called E1, E2, E3, E4, E5, E6 and E7. Table 1 shows the type of products and services they offer. The application aims at comparing the actual strategy map with that obtained with the method. The comparison is made to determine in which extend the proposed method is useful for establishing the causal relationships in a strategy map.

As an illustration, the case of company E2 is described. Figure 4 depicts the initial hierarchical model, where all the nodes (objectives) of a level are connected to all the nodes (objectives) of the subsequent level. The importance of every relationship is estimated using AHP techniques [11]. Then the importance of every relationship is weighed by the importance of corresponding parent node. The result of this operation is shown in Figure 5. Finally, those relationships that account the $80 \%$ of importance are selected and the rests are eliminated. They are highlighted in Figure 5. It should be noted that it was necessary to add "unimportant" relationships to the strategy map in order to avoid leaving nodes without a connection, which is the case of those relationships drawn with a different type of line in Figure 5. For the same reason, all the arcs from the finances perspective to the clients' perspective were maintained.

Finally, Figure 6 shows the strategy map of company E2, which was obtained by deleting all the "unimportant" relationships.

Table 1. Products/services of companies.

\begin{tabular}{cc}
\hline Company & Product/Service \\
\hline E1 & Steel coating \\
E2 & Plastic \\
E3 & Electric generation \\
E4 & Graphic printing \\
E5 & Chemical products \\
E6 & Forestry \\
E7 & Plagues control \\
\hline
\end{tabular}




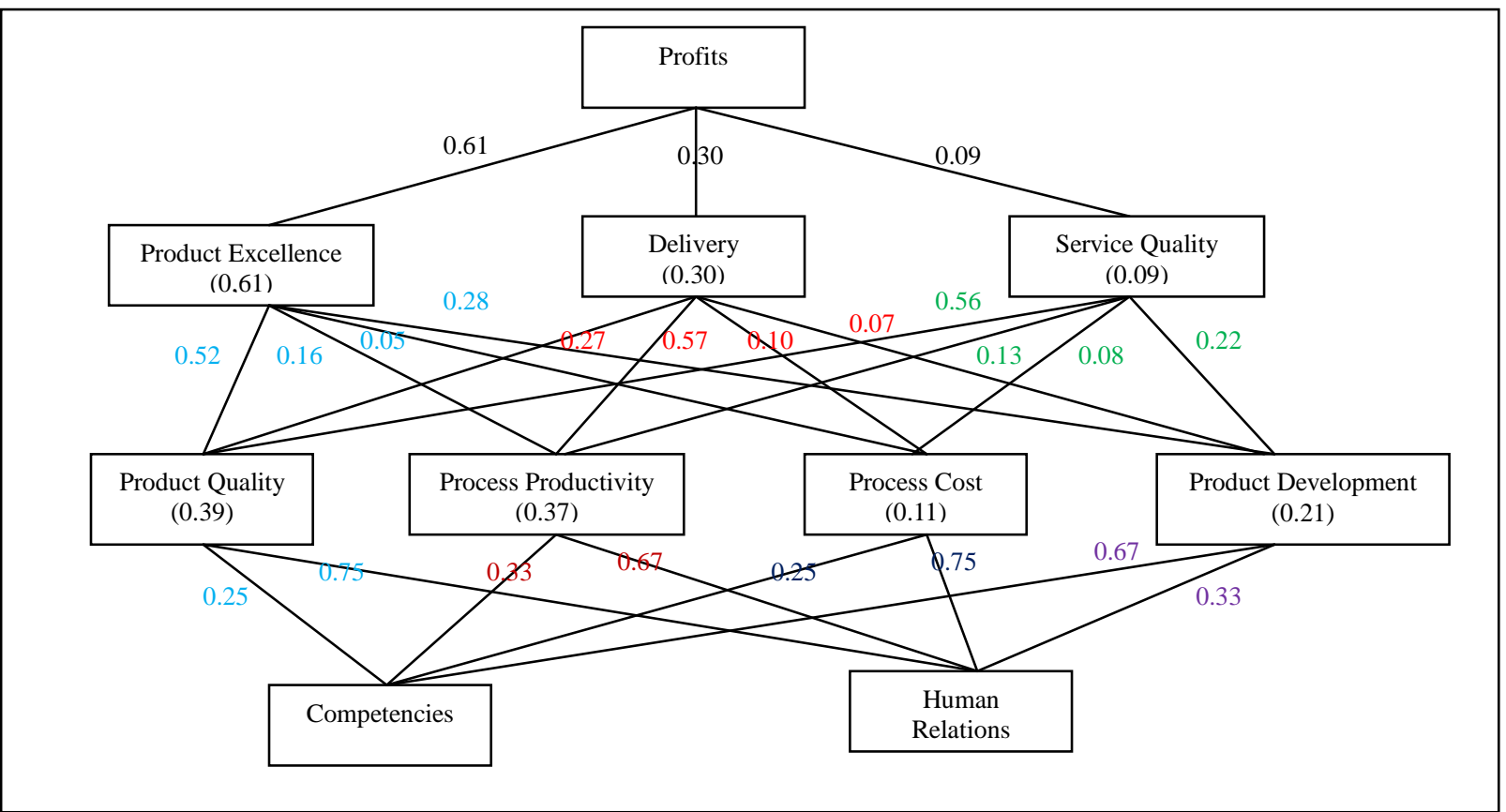

Figure 4. Initial hierarchical model.

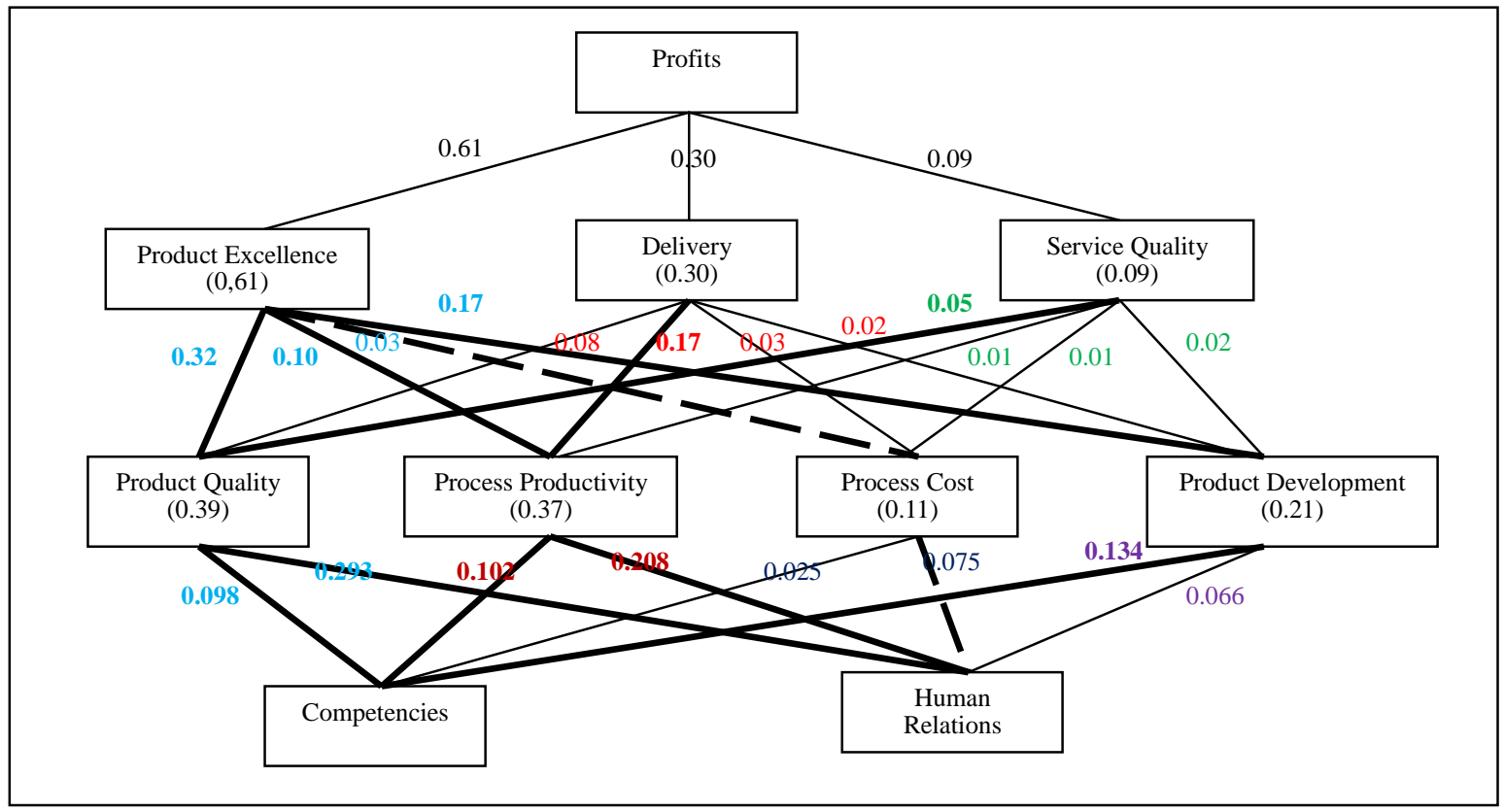

Figure 5. Final hierarchical model.

The following indicators are calculated for the resulting strategy map

$\mathrm{AI}=$ accumulated importance of the relationships between two levels.

$\mathrm{RI}=$ accumulated importance of the relationships between two levels divided by the number of relationships between the levels.

AAI $=$ average (over the levels) of the accumulated importance of the relationships between two levels.
ARI = average (over the levels) of the accumulated importance of the relationships between two levels per number of relationships between the levels.

In the case of company E2 the values are:

Accumulated importance of the relationships between level 2 and $3=83.8 \%$

Accumulated importance of the relationships between level 3 and $4=91.0 \%$

Accumulated importance of the relationships between 


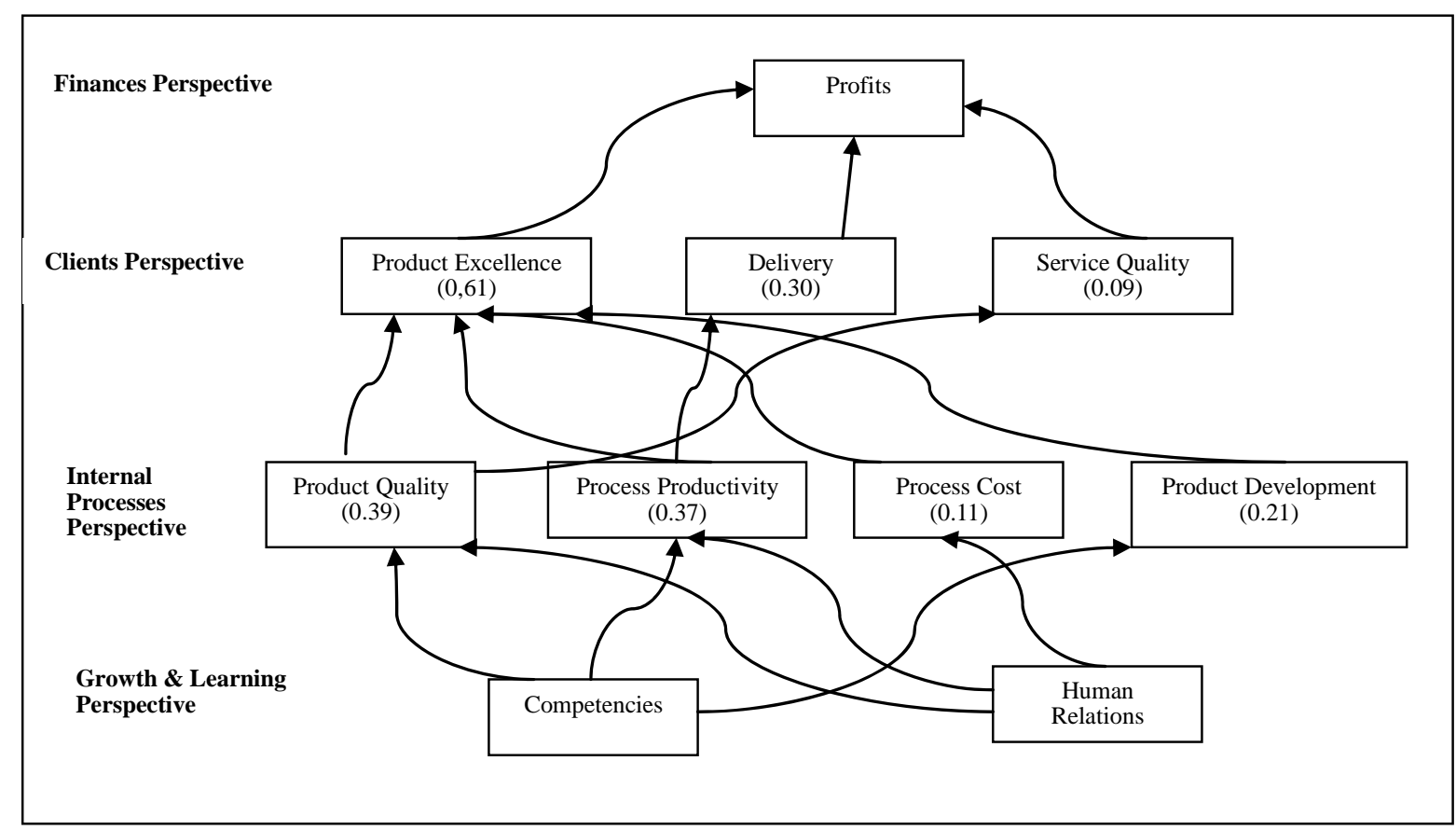

Figure 6. Strategy map of company E2.

two levels divided by the number of relationships between levels 2 and $3=83.8 / 7=14.0 \%$

Accumulated importance of the relationships between two levels divided by the number of relationships between levels 3 and $4=83.8 / 7=15.2 \%$

For the seven companies, these indicators were calculated for the strategy map obtained with the proposed method as well as for the strategy map defined by the company (when available).

The Average Accumulated Indicator (AAI) expresses the percentage of the relationships that are considered “relevant". It is over $80 \%$, because normally it necessary either to add more relationships to connect the bottom level with the top level or the accumulated value of the relationships is not $80 \%$ exactly. The Average of the Accumulated Relationships per Number of Relationships (ARI) is a measure of how relevant is every relationship of the strategy map.

It should be noted that in the case of the propose method, AAI is equal or higher than one of the actual strategy map. It means that the proposed method choose more "relevant" relationships. The value of ARI indicates that, in the case of the proposed method, the importance of the selected relationships is higher, but without increasing the number of relationships.

The figures show that what a method is doing is obtaining a balance between the importance of the relationships and the number of them. In other words, the method tries to reduce the number of relationships of the strategy map and at the same time it tries to increase their importance.
Table 2. Indicators of company E2.

\begin{tabular}{cccc}
\hline & \multicolumn{3}{c}{ Indicators of Strategy Map } \\
\cline { 2 - 4 } Level & AI (\%) & Selected Relationships & RI (\%) \\
\hline $2-3$ & 83.8 & 6 & 14.0 \\
$3-4$ & 91.0 & 6 & 15.2 \\
Average & 87.4 & & 14.6 \\
\hline
\end{tabular}

Table 3. Indicators of the 7 companies.

\begin{tabular}{ccccc}
\hline & \multicolumn{4}{c}{ Indicators (\%) } \\
\cline { 2 - 5 } Firm & $\begin{array}{c}\text { Strategy Map } \\
\text { Proposed Method }\end{array}$ & Current Strategy Map \\
\cline { 2 - 5 } & AAI & ARI & AAI & ARI \\
\hline E1 & 89.7 & 15.8 & 84.5 & 15.8 \\
E2 & 87.4 & 14.6 & 85.1 & 14.2 \\
E3 & 94.2 & 25.1 & N/A & N/A \\
E4 & 86.0 & 16.1 & 61.7 & 14.2 \\
E5 & 80.5 & 8.3 & 60.4 & 7.6 \\
E6 & 89.3 & 15.8 & 62.3 & 10.4 \\
E7 & 85.1 & 18.2 & N/A & N/A \\
\hline
\end{tabular}




\section{Conclusions}

This paper has presented a quantitative method to obtain the causal relationships of a strategy map. It was found that the method obtains relationships that are more important than those which are included in the current strategy maps of the companies under study. Those relationships had been obtained in a traditional way.

This is a good indication that the method may be a better way for obtaining causal relationships in a strategy map than using just intuition.

The method considers that a strategy map can be modeled as a hierarchy, which is not always possible. For this reason, it is proposed to evaluate in future research the use of the Analytic Network Process (ANP).

\section{Acknowledgements}

This work was supported by the University of Santiago of Chile (Project DICYT-USACH Nº 061117QL).

\section{REFERENCES}

[1] A. Neely, "The Evolution of Performance Measurement Research: Developments in the Last Decade and a Research Agenda for the Next," International Journal on of Operations \& Production Management, Vol. 25, No. 12, 2005, pp. 1264-1277. doi:10.1108/01443570510633648

[2] C. F. Gomes, M. M. Yasin and J. V. Lisboa, "Literature Review of Manufacturing Performance Measures and Measurement in an Organizational Context: A Framework and Direction for Future Research,” Journal of Technology Management, Vol. 15, No. 6, 2004, pp. 511-530. doi:10.1108/17410380410547906

[3] R. S. Kaplan and D. P. Norton, "The Balanced Scorecard - measures that Drive Performance,” Harvard Business Review, Jan.-Feb 1992, pp. 71-79.

[4] R. S. Kaplan and D. P. Norton, "The Balanced Scorecard,” Harvard Business School Press, Boston, MA, USA, 1996.

[5] R. Kaplan and D. Norton, "Linking the Balanced Scorecard to strategy,” California Management Review, Vol. 39, No. 1, 1996. doi:10.2307/41165876

[6] R. Y. Kaplan and D. Norton, "Transforming the Balanced Scorecard from performance measurement to strategic management: Part I. American Accounting Association,” Vol. 15. No. 1, 2001.

[7] R. Y. Kaplan and D. Norton, "Transforming the Balanced Scorecard from Performance Measurement to Strategic Management: Part II,” American Accounting Association, Vol. 15. No. 2, 2001.

[8] M. Kunc, "Using Systems Thinking to Enhance Strategy Maps,” Management Decision, Vol. 46, No. 5, pp. 2008, pp. 761-778. doi:10.1108/00251740810873752

[9] R. Kaplan and D. Norton, Strategy Maps, Harvard Business School Press, 2004.

[10] L. Quezada, F. Cordova, P. Palominos, K. Godoy and J.
Ross, "Method for Identifying Strategic Objectives in Strategy Maps,” International Journal of Production Economics, 2009, pp. 122-500.

[11] T. L. Saaty, "Fundamentals of Decision Making and Priority Theory with the Analytical Hierarchy Process," RWS Publications, Pittsburgh, PA, 1994.

[12] R. Saaty, "Decision Making in Complex Environment," RWS Publications, Pittsburgh, PA, 2002.

[13] E. Cheng and H. Li, "Analytic Hierarchy Process, An Approach to Determine Measures for Business Performance," Measuring Business Excellence, Vol. 5, No 3, 2001, pp. 30-36. doi:10.1108/EUM0000000005864

[14] U. Bititci, Suwignjo and A. S. Carrie, "Strategy Management through Quantitative Modelling of Performance Measurement Systems,” International Journal of Production Economics, Vol. 69, 2001, pp. 15-22. doi:10.1016/S0925-5273(99)00113-9

[15] H. Lee, W. Kwak and I. Han, "Developing a Business Performance Evaluation System: An Analytic Hierarchical Model,” The Engineering Economist, Vol. 15, 2005, pp. 108-127.

[16] J. Sarkis, "Quantitative Models for Performance Measurement Systems-alternate Considerations,” International. Journal of Production Economics, Vol. 86, 2003, pp. 81-90. doi:10.1016/S0925-5273(03)00055-0

[17] G. T. Temur, E. Emeksizoghlu and S. Gozlu, “A Study of Performance Measuremet of a Plastic Packaging Organization's System by AHP Modelling,” PICMET 2007 Proceedings, 5-7 August, Portland, Oregon, USA, 2007.

[18] M. Yurdakul, "Measuring Long Term Performance of a Manufacturing Firm Using the Analytic Network Process (ANP) Approach,” International Journal of Production Research, Vol. 41, No. 11, 2003, pp. 2501-2529.

[19] M. Yurdakul and Y. T. Ic, "Development of a Performance Measurement Model for Manufacturing Companies Using the AHP and TOPSIS Approaches,” International Journal of Production Research, Vol. 23, No. 21, 2005, pp. 4609-4641

[20] T. L. Saaty, "Decision Making with Dependence and Feedback: The Analytic Network Process," 2nd Edition. RWS Publications, Pittsburgh, PA, 2001.

[21] H. Huang, M. Lai and L. Lin, "Developing Strategic Measurement and Improvement for the Biopharmaceutical Firm: Using the BSC Hierarchy,” Expert Systems and Applications, Vol. 38, No. 5, 2011, pp. 4875-4881.

[22] M. Tseng, "Implementation and Performance Evaluation Using the Fuzzy Network Balanced Scorecard,” Computers \& Education, Vol. 55, 2010, pp. 188-201.

[23] I. Yuksel and M. Dagdeviren, "Using the Fuzzy Analytic Network Process (ANP) for Balanced Scorecard (BSC): A Case Study for a Manufacturing Firm,” Expert System with Applications, Vol. 37, 2010, pp. 1270-1278.

[24] L. Quezada and D. Quintero, "Quantitative Model for the Design of a Strategy Map,” Proceedings of the 21th International Conference on Production Research, Stuttgart, Germany, 31 July- 4 August, 2011. 